\title{
THEORETICAL EVALUATION OF UNIAXIAL FLEXURAL BEHAVIOR OF ULTRA HIGH PERFORMANCE REINFORCED CONCRETE MEMBERS
}

\begin{abstract}
Ultra High Performance Concrete (UHPC) is an advanced cementitious composite consisting of a dense high strength matrix and fibers. UHPC is used in various fields worldwide due to its high characteristics mainly high compressive strength. The last researches studied the UHPC from the material level as the main components and its characteristics that vary from those of conventional concrete. So, UHPC need to be studied more from the structural level to predict the flexure capacity, ductility and serviceability. This paper runs a numerical data for structural behavior of UHPC with the concrete compressive strength parameter. Five finite element models were developed and solved by ANSYS software to examine the effect of the concrete compressive strength on structural behavior of UHPC simple beams. The results showed that increasing the concrete compressive strength from 115 to $150 \mathrm{MPa}$ led to increase the flexure capacity by $5.4 \%$ and remains constant from 150 to $215 \mathrm{MPa}$. While, the stiffness was decreased by $35 \%$ from 115 to $215 \mathrm{MPa}$.
\end{abstract}

Ahmed A. Abdel-Bary* ${ }^{1}$, Ayman Hussein Hosny ${ }^{1}$ and Wael M. Montaser ${ }^{2}$

${ }^{1}$ Structural Engineering Dep, Ain Shams University, Cairo, Egypt.

${ }^{2}$ Building and Construction Dep, October 6 University, Giza, Egypt.

*Corresponding Author Email: Ahmedrbary@gmail.com

KEYWORDS: Ultra High Performance Concrete (UHPC), Structural, ANSYS, Flexure Capacity, Stiffness.

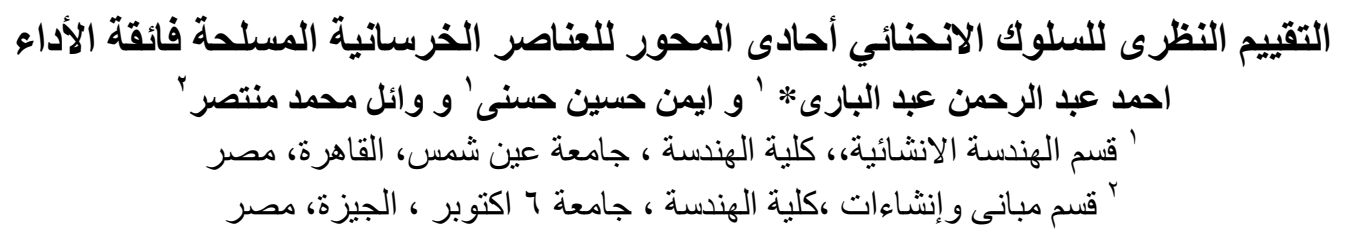

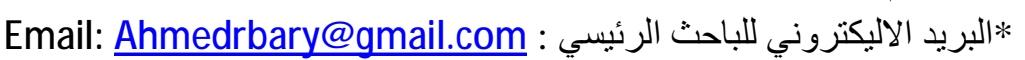

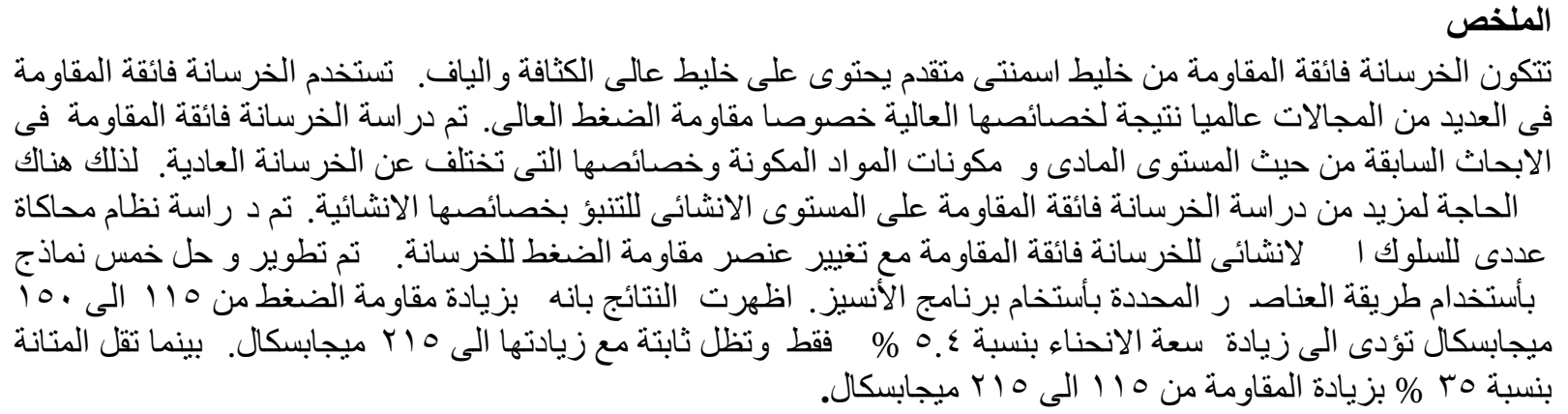




$$
\text { الكلمات المفتاحية: الخرسانة فائقة المقاومة، انثائى، انسيز، سعة الانحناء، المتانة. }
$$

\section{INTRODUCTION}

Concrete is currently the most widely used building material. Although many structures are built of concrete, there are still some limitations related to the use of conventional concrete, such as low tensile strength, almost no ductility and compressive strength up to $60 \mathrm{MPa}$. High strength concrete is a new material that can maximize the advantages of concrete due to its high compressive strength up to $100 \mathrm{MPa}$ but it shows less ductility than conventional concrete. UHPC may be able to overcome ordinary concrete limitations. This is attributed to its high properties such as high tensile strength, high range of compressive strength and high ductility compared to conventional concrete. The Association Française de Génie Civil (AFGC) [1] classifies UHPC as having a compressive strength greater than $150 \mathrm{MPa}(22 \mathrm{ksi})$ and having internal fiber reinforcement to ensure non brittle behavior and high binder content with special aggregates. The US Army Engineering Research and Development Center (ERDC) [2] classify UHPC as cementitious materials with unconfined compressive strengths ranging from 138 to 276 $\mathrm{MPa}$ (20 to $40 \mathrm{ksi}$ ). In UHPC, the aggregates are a set of inclusions in a continuous matrix and the aggregate diameters are much smaller. Thus, the compressive force can be transmitted by the matrix instead of by a rigid skeleton of aggregates which reduces the stresses that develop at the paste aggregate interface. The transmittal of stresses by both the aggregates and the surrounding matrix in UHPC leads to a much more uniform stress distribution which can reduce potential for shear and tensile cracking at the interface. In addition to reduce the water to cement ratio typically close to 0.20 compared with a w/c ratio of $0.30-0.50$ for conventional concrete [3].

Several types of UHPC have been developed and the main difference between the types of UHPC is the type and amount of fibers used. The four main types of UHPC are Ceracem/BSI, compact reinforced composites (CRC), multi-scale cement composite (MSCC) and reactive powder concrete (RPC). Ceracem/BSI includes a coarse aggregate, which are eliminated in the other types of UHPC [4]. CRC and MSCC both use high amounts of fiber and use different fiber sizes than those used in RPC. RPC's steel fibers occupy two percent of the concrete mixture by volume [5]. Most studies on UHPC have focused on special concrete materials with characteristics that differ from those of conventional concrete at the material level. However, few researches are available on the flexural capacity, ductility, reinforcement ratio and serviceability of UHPC beams at the structural level that can predict the overall performance.

In Hwan et al. [6] define UHPC as an advanced cementitious composite consisting of a dense high strength matrix and fibers (a high quantity of cement, fine aggregate, silica fume, low quantity of water, high range water reducing agent and incorporates large amounts of fibers). They provide a detailed presentation of experimental test results for the flexural behavior of UHPC beams with compressive strength equal to $190 \mathrm{MPa}$. The tested parameters included the amount of rebar with rebar ratios less than $0.02(0.006-0.009-0.012)$ and steel fibers with volumetric ratio of $2 \%$ and the placing method for UHPC. UHPC was effective at controlling cracks and showed a ductile behavior with a ductility index ranging between 1.60 and 3.75. The flexure capacity was increased with increasing the rebar ratio. In addition to placing of UHPC from the end of the beam provides better structural performance than placing UHPC from midspan.

M. Kamal et al. [7] examine the behavior of ultra high performance concrete beams with compressive strength equal to 130 and $135 \mathrm{MPa}$. The main variables were the type of fibers (steel and polypropylene) and the amount of longitudinal reinforcement (0.012 and 0.017) in addition to the existence or absence of the web reinforcement. The steel fibers were more efficient in increasing both initial and ultimate loads. In beams without web reinforcement, the shear strength and ultimate loads were increased with using fibers. The flexure capacity was increased by increasing the reinforcement ratio. The number of cracks was increased at failure load due to the 
use of fibers which led to reduce the width of cracks. This led to increase the stiffness and the flexure capacity.

Doo and Young [8] evaluate the structural performance of ultra high performance concrete beams with compressive strength from 200 to $232 \mathrm{MPa}$. The tested parameters included the reinforcement ratio $(\mathrm{q}=0.94 \%$ and $1.50 \%)$ and steel fiber type (smooth and twisted steel fibers). In addition, smooth steel fibers lengths $(\mathrm{Lf}=13,19.5$, and $30 \mathrm{~mm})$ and twisted steel fiber length $(\mathrm{Lf}=30 \mathrm{~mm})$. Test results indicated that the addition of steel fibers significantly improved the load carrying capacity, post-cracking stiffness and cracking response but it decreased the ductility. Adding steel fibers with $2 \%$ volume led to 27 to $54 \%$ higher load carrying capacity and 13 to $73 \%$ lower ductility were obtained. In addition, increasing the length of smooth steel fibers and the use of twisted steel fibers led to the improvements of post peak response and ductility and no change noticeable in the load carrying capacity, post-cracking stiffness and cracking response were obtained according to the fiber length and type.

M. Singh et al. [9] investigate the efficacy of the hybrid approach of validating the existing UHPC model to study the behavior of large-scale structural members. Four full scale beams with varied spans and cross-sections were fabricated and numerical models were developed and validated with the test results. Venkatesh Kodur et al. [10] analyzes failure characteristics of UHPC beams under flexural and shear loading. Four large scale beams with low tensile reinforcement ratio and no shear reinforcement. Results indicate that UHPC beams exhibit a distinct cracking pattern with multiple micro cracks at initial stages and a singular macro crack at the critical section. Absence of shear reinforcement in UHPC beams did not lead to any reduction in either ductility or moment capacity of the beams even under dominant shear loading. DooYeol Yoo et al. [11] investigates the effects of steel fiber type on the pullout and tensile performance of UHPC with four different types of steel fibers (straight, twisted, hooked, and half-hooked). Test results indicated that better pullout resistance was obtained in the deformed (twisted, hooked, and half-hooked). While, the best tensile performance of UHPC was achieved by incorporating straight steel fibers, followed by the twisted, half-hooked, and hooked steel fibers

The prime objective of the proposed research is to examine the basic structural behavior of UHPC simple beams with the concrete compressive strength. The study will focus on flexural capacity, cracking and failure pattern, serviceability and ductility. A finite element analyses will be done to simulate the structural behavior of UHPC simple beams.

\section{NUMERICAL PROGRAM (ANSYS)}

The main concept of using numerical techniques is to invent close solutions to partial differential equations with required precision. The method includes dividing the body into finite elements connected to each other by nodes to gain approximate solutions to the field problem in question.

\subsection{Materials and Elements Properties}

We used nonlinear equation [12] to obtain stress-strain relationship from the same approach for different Fcu as shown in Eq. 1. We gathered data for UHPC from previous researches [6] [8] [13] [14] and applying it in Eq. 1 to get the properties of different compressive strength beams. Finally, we compared the stress strain curve for $\mathrm{Fcu}=190 \mathrm{MPa}$ from the nonlinear equation and experimental test for In Hwan et al. [6]. The results agreed very well with experimental test as shown in Fig. 1. The elements will be used to simulate the materials are Soild65 for UHPC, Link180 for compression, tension and stirrups steel and Solid185 for support and loading plates [15]. Poisson's ratio was assumed to be constant for all specimens and equal to 0.30. Properties of UHPC for all specimens are shown Table 1. The multilinear isotropic stress strain curves used to simulate UHPC is shown in Fig. 2. The Failure Criteria of UHPC was shown in Table 2. 


$$
\frac{f}{f_{\mathrm{o}}}=\frac{R\left(\frac{\epsilon}{\mathrm{e}_{\mathrm{o}}}\right)}{1+(R-1)\left(\frac{\epsilon}{\epsilon_{\mathrm{e}}}\right)^{b}} \quad \beta=\mathrm{R} /(\mathrm{R}-1)
$$

$\mathrm{R}=$ material parameter depending on the shape of the stress strain curve $=\mathrm{E}_{\mathrm{c}} / \mathrm{E}_{\mathrm{o}}$ $\mathrm{E}_{\mathrm{c}}=$ modulus of elasticity of concrete, $\mathrm{E}_{\mathrm{o}}=\max$. Stress $\mathrm{f}_{\mathrm{o}} /$ strain at max. Stress $\epsilon_{\mathrm{o}}$ $\mathrm{E}_{\mathrm{o}}=0.000875\left(\mathrm{f}_{\mathrm{o}}\right)^{0.3}, \mathrm{E}_{\mathrm{c}}=4400\left(\mathrm{~F}_{\mathrm{cu}}\right)^{0.45}, \mathrm{~F}_{\mathrm{t}}=0.60\left(\mathrm{~F}_{\mathrm{cu}}\right)^{0.497}$

For steel reinforcement the Yield Stress (Fy) was 240 for stirrups and $600 \mathrm{MPa}$ for tension and compression steel, as well as the Hardening Modulus (tangent modulus of the plastic region) of steel was $2100 \mathrm{MPa}$ for the bilinear model. Elastic Modulus (EX) was 2x105 MPa and Poisson's Ratio (PRXY) was assumed to be 0.3. For Loading and Supporting Steel Plates were modeled as an elastic linear isotropic material with Elastic Modulus (EX) equal $2 \times 10^{7}$ and Poisson's Ratio (PRXY) equal 0.30. Perfect bond exists between concrete and steel reinforcement. To check the validity of the numerical model, we compare it with simple rectangle beam with $190 \mathrm{MPa}$ stressstrain curve (R14 with rebar ratio $1.2 \%)$ ) tested by In Hwan et al. [6] with all properties, loads and boundary conditions. Fig. 3 and Table 3 show a comparison between the load $\square$ midspan deflection curve and differences for beam R14 from experimental test and Ansys. So, the finite element method can predict the experimental results with a good precision.

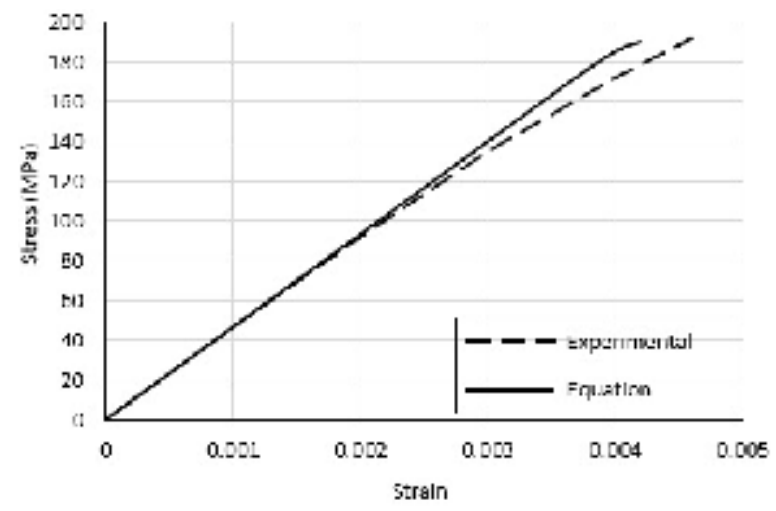

Fig. 1. Comparative Stress-Strain Curve for UHPC

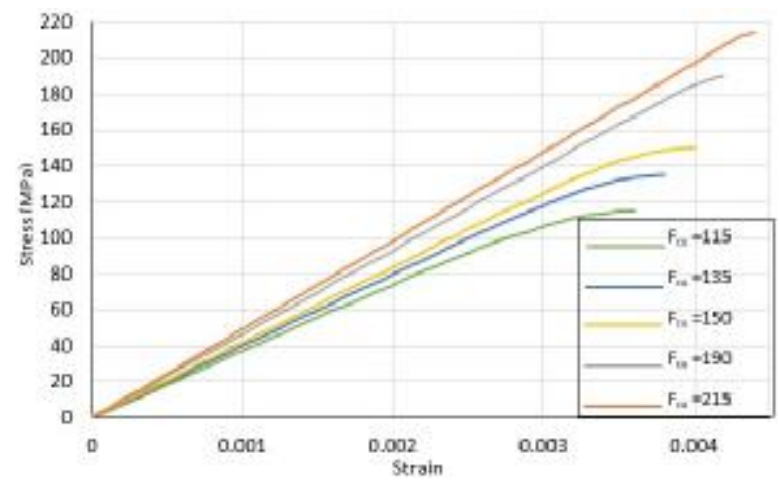

Fig. 2. Multilinear Isotropic Stress-Strain Curve for UHPC from Nonlinear Equation 


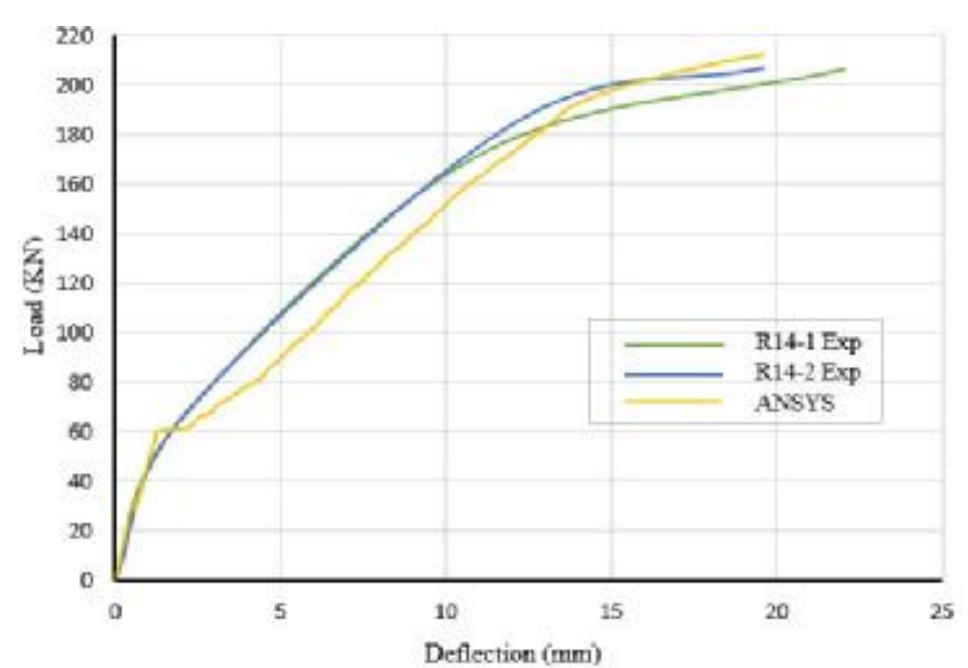

Fig. 3. Comparison of Experimental and ANSYS Load-Midspan Deflection Curves for Beam R14

Table 1. Material Properties from Nonlinear Equations

\begin{tabular}{|c|c|c|}
\hline $\mathrm{F}_{\mathrm{cu}}(\mathrm{MPa})$ & $\mathrm{F}_{\mathrm{t}}(\mathrm{MPa})$ & $\mathrm{E}_{\mathrm{c}}(\mathrm{MPa})$ \\
\hline 115 & 6.25 & 37219 \\
\hline 135 & 6.77 & 40004 \\
\hline 150 & 7.14 & 41946 \\
\hline 190 & 8.027 & 46654 \\
\hline 215 & 8.536 & 49323 \\
\hline
\end{tabular}

Table 2. Failure Criteria Constants of UHPC

\begin{tabular}{|c|c|}
\hline Open Shear Transfer Coef. & 0.40 \\
\hline Closed Shear Transfer Coef. & 0.95 \\
\hline Uniaxial Cracking Stress & $12 \mathrm{MPa}$ \\
\hline Uniaxial Crushing Stress & $190 \mathrm{MPa}$ \\
\hline Tensile Crack Factor & 0.80 \\
\hline
\end{tabular}

Table 3. Comparisons between Experimental and ANSYS Results of Beam R14

\begin{tabular}{|c|c|c|c|c|c|}
\hline \multirow[t]{2}{*}{ State } & \multirow[t]{2}{*}{ ANSYS load (KN) } & \multicolumn{3}{|c|}{ EXP load $(\mathrm{KN})$} & \multirow[t]{2}{*}{ Difference } \\
\hline & & R14-1 & R14-2 & Average & \\
\hline Cracking & 62 & 62.6 & 67.8 & 65.2 & $-4.90 \%$ \\
\hline Yielding & 192 & 172.1 & 185.1 & 178.6 & $7.50 \%$ \\
\hline Failure & 212 & 206.2 & 206.8 & 206.5 & $2.66 \%$ \\
\hline \multirow[t]{2}{*}{ State } & \multirow{2}{*}{$\begin{array}{l}\text { ANSYS deflection } \\
(\mathrm{mm})\end{array}$} & \multicolumn{3}{|c|}{ EXP deflection $(\mathrm{mm})$} & \multirow[t]{2}{*}{ Difference } \\
\hline & & R14-1 & R14-2 & Average & \\
\hline Yielding & 13.9006 & 11.05 & 12.14 & 11.595 & $19.88 \%$ \\
\hline Failure & 19.5967 & 22.03 & 19.62 & 20.825 & $-5.90 \%$ \\
\hline
\end{tabular}




\subsection{Beam Specimen Details and Methodology}

The geometrical properties of all tested beams were remained constant with R-sec beam with dimensions $250 \mathrm{~mm}$ x $500 \mathrm{~mm}$ x $5000 \mathrm{~mm}$. The beams were simply supported under four-point loading as shown in Fig. 4. The steel loading and supporting plates were $25 \mathrm{~mm}$ x $100 \mathrm{~mm}$ x 250 $\mathrm{mm}$. The real constant was the cross-sectional area for steel reinforcement. The details of beams and the arrangement of steel reinforcement were shown in Table 4 and Fig. 5. Volumes created in ANSYS was shown in Fig. 6. The overall size of the mesh used is $30 \mathrm{~mm}^{2}$. Number of elements were 18550 . We modeled a half of each full beam by taking advantage of the symmetry of the beams about one plane. Nodes defining a vertical plane through the beam mid-section define a plane of symmetry. To model the symmetry the nodes on this plane must be constrained in the perpendicular direction. Therefore, these nodes have a degree of freedom constraint UX = 0 . The support was modeled as a roller. A line of nodes on the middle of the support plate were given constraint in the UY, and UZ directions, applied as constant values of 0 . The flexure force is applied at the steel plate and applied across all the nodes on the top face of plate. The load was applied at equal increments of $2 \mathrm{KN}$ for the half beam models. Setting solution parameters involves defining the analysis type (nonlinear static) and common analysis options for an analysis, as well as specifying load step options for it. The maximum and minimum load step sizes are required for the automatic time stepping. Typical commands utilized in the analysis and the Convergence Criteria used are shown in Table 5.

Table 4. Details of the Tested Beams

\begin{tabular}{|c|c|c|c|c|c|c|c|}
\hline Specimen & $\begin{array}{l}\text { Dimensions } \\
(\mathrm{cm})\end{array}$ & cover & $\begin{array}{c}\mathrm{F}_{\mathrm{cu}} \\
(\mathrm{MPa})\end{array}$ & $\begin{array}{c}\text { Used RFT } \\
\text { Ratio }\end{array}$ & RFT & Comp RFT & Stirrups \\
\hline $\mathrm{B}_{1}$ & \multirow{5}{*}{$25 \times 50 \times 500$} & \multirow{5}{*}{$5 \mathrm{~cm}$} & 115 & \multirow{5}{*}{$1.6 \%$} & \multirow{5}{*}{$\begin{array}{l}8 D 18 \\
(4+4)\end{array}$} & \multirow{5}{*}{ 2D18 } & \multirow{5}{*}{$8 \mathrm{D} 10 / \mathrm{m}$} \\
\hline $\mathrm{B}_{2}$ & & & 135 & & & & \\
\hline $\mathrm{B}_{3}$ & & & 150 & & & & \\
\hline$\overline{B_{4}}$ & & & 190 & & & & \\
\hline $\mathrm{B}_{5}$ & & & 215 & & & & \\
\hline
\end{tabular}

Table 5. Nonlinear Analysis Control Commands

\begin{tabular}{|l|l|}
\hline Analysis Options & Small Displacement Static \\
\hline Time at End of Load Step & Variable \\
\hline Automatic Time Stepping & On \\
\hline Substep Size & $2 \mathrm{KN}$ \\
\hline Max Substep Size & $2 \mathrm{KN}$ \\
\hline Min Substep Size & $1 \mathrm{KN}$ \\
\hline Write Items to Results File & Write Every Substep \\
\hline Equation Solvers & Program chosen solver \\
\hline Line Search & On \\
\hline $\begin{array}{l}\text { Maximum number of } \\
\text { iteration }\end{array}$ & 50 \\
\hline \multicolumn{2}{|c|}{ Convergence Criteria Parameters } \\
\hline Label & $\mathrm{U}$ \\
\hline Ref. Value & Calculated \\
\hline Tolerance & 0.01 \\
\hline Norm & L2 \\
\hline
\end{tabular}




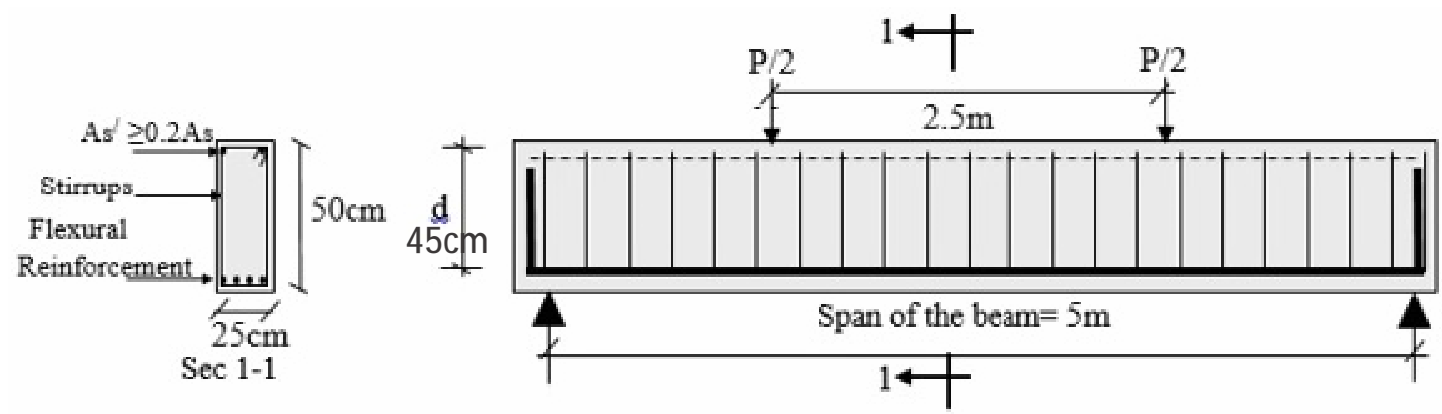

Fig. 4. Details of the Tested Beams

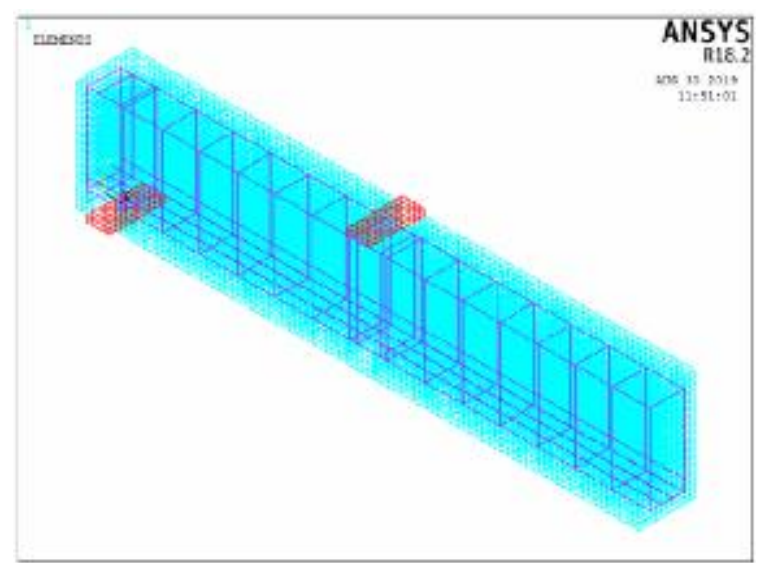

Fig. 5. Arrangement of RFT for Half of Beam

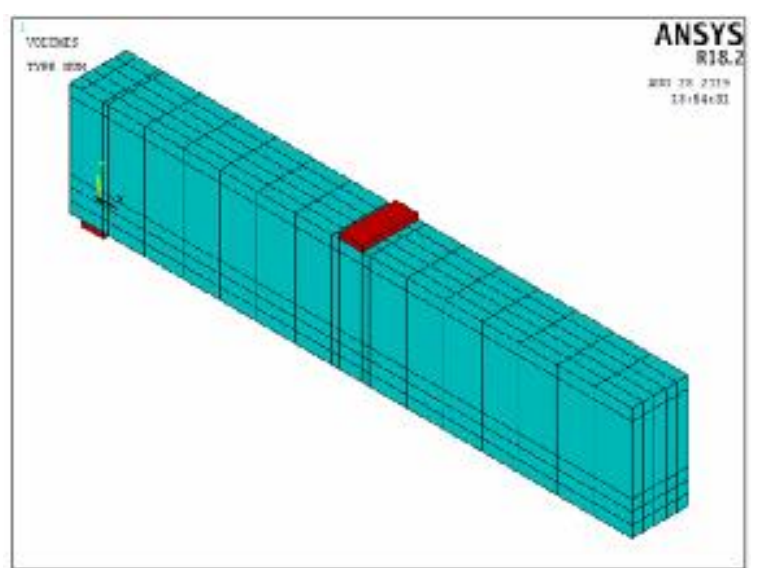

Fig. 6. Volume Created for Half of Beam

\section{RESULTS AND DISCUSSION}

\subsection{Load versus Deflection Response}

The load-midspan deflection curves for all test specimens are shown in Fig. 7. In addition to the loads and deflections at the first cracking state, steel rebar yielding state, and peak state are summarized in Table 6. The first cracking load was $136 \mathrm{KN}$ for beam $\mathrm{B}_{1}$ with $115 \mathrm{MPa}$ compressive strength, was increased with increasing the compressive strength by $8.82,11.77$, 26.47 and $32.35 \%$ for beam $\mathrm{B}_{2}, \mathrm{~B}_{3}, \mathrm{~B}_{4}$ and $\mathrm{B}_{5}$ with increasing the compressive strength from $135,150,190$ and $215 \mathrm{MPa}$ respectively. The deflection at first cracking state was $1.866 \mathrm{~mm}$ for beam $\mathrm{B}_{1}$. It was increased very slight by $2.2,0.7,3.8$ and 3.3 for beam $\mathrm{B}_{2}, \mathrm{~B}_{3}, \mathrm{~B}_{4}$ and $\mathrm{B}_{5}$ respectively. The stiffness at first cracking state was increased by $6.49,11,21.85$ and $28.10 \%$ for $\mathrm{B}_{2}, \mathrm{~B}_{3}, \mathrm{~B}_{4}$ and $\mathrm{B}_{5}$ respectively compared to stiffness of $\mathrm{B}_{1}$. The load was increased until the steel yielded. The yield load was $738 \mathrm{KN}$ for beam $\mathrm{B}_{1}$, was increased very slight by $0.54,2.98,1.90$ and $2.44 \%$ for $\mathrm{B}_{2}, \mathrm{~B}_{3}, \mathrm{~B}_{4}$ and $\mathrm{B}_{5}$ respectively. The deflection at yielding was $27.136 \mathrm{~mm}$ for beam $\mathrm{B}_{1}$. It was decreased very slight by $2.2,0.7,3.8$ and 3.3 for beam $\mathrm{B}_{2}, \mathrm{~B}_{3}, \mathrm{~B}_{4}$ and $\mathrm{B}_{5}$ respectively. The stiffness at yielding was increased slightly by $0.80,3.30,5.15$ and $7.80 \% \mathrm{~B}_{2}$, $\mathrm{B}_{3}, \mathrm{~B}_{4}$ and $\mathrm{B}_{5}$ respectively compared to stiffness of $\mathrm{B}_{1}$. The load was increased until the peak load. The peak load was $870 \mathrm{KN}$ for beam $\mathrm{B}_{1}$. The flexure capacity (peak load) was increased slighlty by $1.95,5.29,5.52$ and $5.40 \%$ for $\mathrm{B}_{2}, \mathrm{~B}_{3}, \mathrm{~B}_{4}$ and $\mathrm{B}_{5}$ respectively. The deflection at peak state was $45.765 \mathrm{~mm}$ for beam $\mathrm{B}_{1}$. It was increased highly by $39.4,65.4,87.4$ and 62.7 for beam $\mathrm{B}_{2}, \mathrm{~B}_{3}, \mathrm{~B}_{4}$ and $\mathrm{B}_{5}$ respectively. The stiffness at peak state was decreased by $27.15,36.35,43.71$ and $35.20 \%$ for $\mathrm{B}_{2}, \mathrm{~B}_{3}, \mathrm{~B}_{4}$ and $\mathrm{B}_{5}$ respectively compared to stiffness of $\mathrm{B}_{1}$. 

MEMBERS

Table 6. Loads and Deflections for all Loading States

\begin{tabular}{|c|c|c|c|c|c|c|c|}
\hline \multirow{2}{*}{ Beam } & \multicolumn{2}{|c|}{ First cracking } & \multicolumn{2}{c|}{ Yielding state } & \multicolumn{2}{c|}{ Peak state } & Ductility index \\
\cline { 2 - 8 } & $\begin{array}{c}\mathrm{P}_{\mathrm{cr}} \\
(\mathrm{KN})\end{array}$ & $\begin{array}{c}\Delta_{\mathrm{cr}} \\
(\mathrm{mm})\end{array}$ & $\begin{array}{c}\mathrm{P}_{\mathrm{y}} \\
(\mathrm{KN})\end{array}$ & $\begin{array}{c}\Delta_{\mathrm{y}} \\
(\mathrm{mm})\end{array}$ & $\begin{array}{c}\mathrm{P}_{\mathrm{p}} \\
(\mathrm{KN})\end{array}$ & $\begin{array}{c}\Delta_{\mathrm{p}} \\
(\mathrm{mm})\end{array}$ & $\mu_{\mathrm{p}}=\Delta_{\mathrm{p}} / \Delta_{\mathrm{y}}$ \\
\hline $\mathrm{B}_{1}$ & 136 & 1.866 & 738 & 27.136 & 870 & 45.765 & 1.67 \\
\hline $\mathrm{B}_{2}$ & 148 & 1.907 & 742 & 27.058 & 884 & 63.807 & 2.36 \\
\hline $\mathrm{B}_{3}$ & 152 & 1.879 & 760 & 27.044 & 916 & 75.671 & 2.80 \\
\hline $\mathrm{B}_{4}$ & 172 & 1.937 & 752 & 26.296 & 918 & 85.783 & 3.26 \\
\hline $\mathrm{B}_{5}$ & 180 & 1.928 & 756 & 25.785 & 917 & 74.443 & 2.89 \\
\hline
\end{tabular}

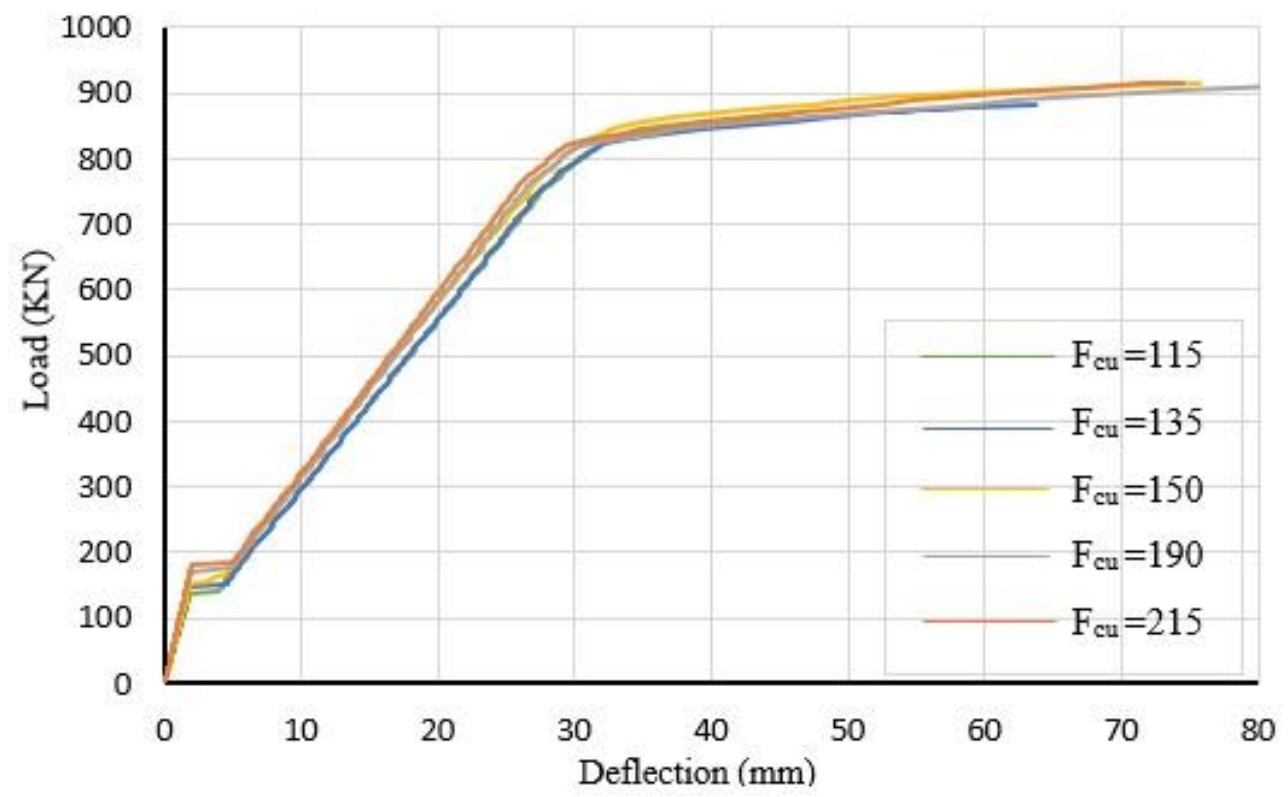

Fig. 7. Load-Midspan Deflection Curve for $B_{1}, B_{2}, B_{3}, B_{4}$ and $B_{5}$

\subsection{Crack and Failure Patterns}

Cracks were not observed when the load was increased linearly at the beginning of the test. The cracks were observed at first crack load with micro-cracks occurred at the bottom face of the beam between the loading points where the beam was subjected to pure bending. Vertical flexural cracks were formed perpendicular to the maximum principle stress direction toward the top face. When applied loads increased, vertical flexural cracks were spread horizontally from the mid-span to the support. The propagation of horizontal and vertical cracks and width were showed approximately the same behavior by increasing the compressive strength. The failure mode for all beams were flexure failure before UHPC reach the compressive strength as shown from Fig. 8 to Fig. 12. 


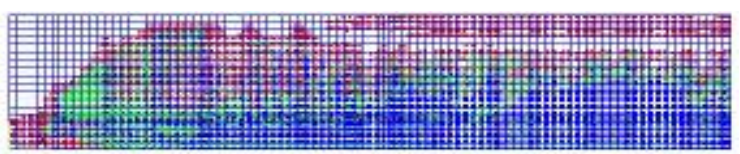

Fig. 8. The propagation of cracks at failure load for half beam $B_{1}$

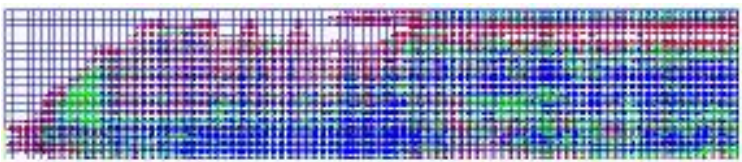

Fig. 9. The propagation of cracks at failure load for half beam $B_{2}$

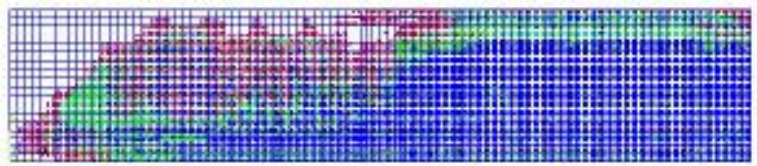

Fig. 10. The propagation of cracks at failure load for beam $\mathbf{B}_{3}$

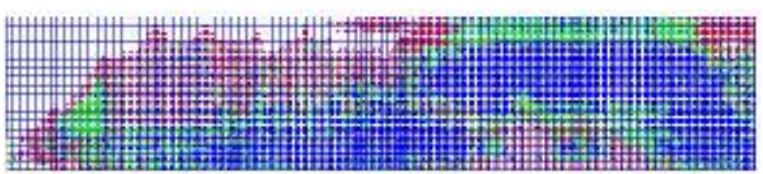

Fig. 11. The propagation of cracks at failure load for half beam $B_{4}$

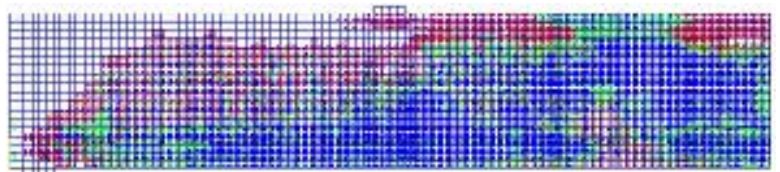

Fig. 12. The propagation of cracks at failure load for half beam $\mathrm{B}_{5}$

\subsection{Ductility}

The ductility of a concrete structure can be used as a measure of the resistance of the structural member or structural system to deformation during transition from the elastic zone to the plastic zone until failure. This can also be interpreted as a measure of the energy absorption capacity of the structural member. In general the ductility of a concrete structure can be quantified via the ductility index, which can be expressed in terms of the deflection ductility index, the rotational ductility index or curvature ductility index. Midspan deflection measurement is only necessary for the deflection ductility index and its measurement is comparatively easy. In this study, the deflection ductility index based on deflection, as expressed in Eq. (2), was used to examine the ductility characteristics of the members.

$\mu_{\mathrm{p}}=\Delta_{\mathrm{p}} / \Delta_{\mathrm{y}}$

Where $\mu$ is the ductility index of the member, $\Delta_{\mathrm{p}}$ is the deflection of the member at the peak load, and $\Delta_{\mathrm{y}}$ is the deflection of the member at the yielding load. Because of all beams behave with strain hardening with ascending portion not strain softening with descending portion, we could measure the ductility index with the peak deflection only not with the ultimate deflection (about $80 \%$ deflection of peak deflection on descending portion). Table 6 show the ductility index for beams. The ductility index for $\mathrm{B}_{1}$ was 1.67 . The ductility index was influenced and increased by increasing the compressive strength expect $\mathrm{B}_{5}$ showed lower ductility index than $\mathrm{B}_{4}$ with high compressive strength. The increase in ductility was $41.32,67.66,95.21$ and $73.05 \%$ for $\mathrm{B}_{2}, \mathrm{~B}_{3}$, $\mathrm{B}_{4}$ and $\mathrm{B}_{5}$ respectively compared to $\mathrm{B}_{1}$. In general the ductility of beams increase with increasing the compressive strength. 


\subsection{Load versus Strain Response}

\subsubsection{Compressive UHPC Strain}

For all specimens, the compressive concrete strain response experienced approximately a linear behavior up to yielding state, similar to deflection response. After the first crack substep, high strain hardening occurred due to instability of the beam and reduction in stiffness until the reinforcement counteracts this on the next load substep. Strain hardening continued until failure. The first crack for $\mathrm{B}_{1}, \mathrm{~B}_{2}, \mathrm{~B}_{3}, \mathrm{~B}_{4}$ and $\mathrm{B}_{5}$ was $175,178,184,176$ and 180 respectively. So the strain at first cracking load was approximately the same value for different compressive strength beams.. Strain hardening ratio was decreased slightly by increasing the compressive strength. The strain at failure hadn't influence by increasing the compressive strength. The maximum midspan compressive concrete strain prior to failure was 2030, 2320, 2620, 2320 and $2290 \mu \varepsilon$ for $\mathrm{B}_{1}, \mathrm{~B}_{2}, \mathrm{~B}_{3}, \mathrm{~B}_{4}$ and $\mathrm{B}_{5}$ respectively. Fig. 13 shows comparative compressive UHPC strain with loads for compressive strength beams.

\subsubsection{Tensile steel stress}

The reinforcement for all beams yielded at the same strain with an average equal to $3000 \mu \varepsilon$. The maximum midspan tension steel strain prior to failure was 1050, 1390, 1900, 2020 and $2020 \times 10^{-}$ ${ }^{5}$ for $\mathrm{B}_{1}, \mathrm{~B}_{2}, \mathrm{~B}_{3}, \mathrm{~B}_{4}$ and $\mathrm{B}_{5}$ respectively. The steel strain at failure was increased by $32.38,80.95$, 92.38 and 92.38 for $\mathrm{B}_{2}, \mathrm{~B}_{3}, \mathrm{~B}_{4}$ and $\mathrm{B}_{5}$ compared to strain of $\mathrm{B}_{1}$. Compressive strength had influence in steel strain. Increasing the compressive strength lead to increase in steel strain. Fig. 14 shows comparative tensile steel strain with loads for compressive strength beams.

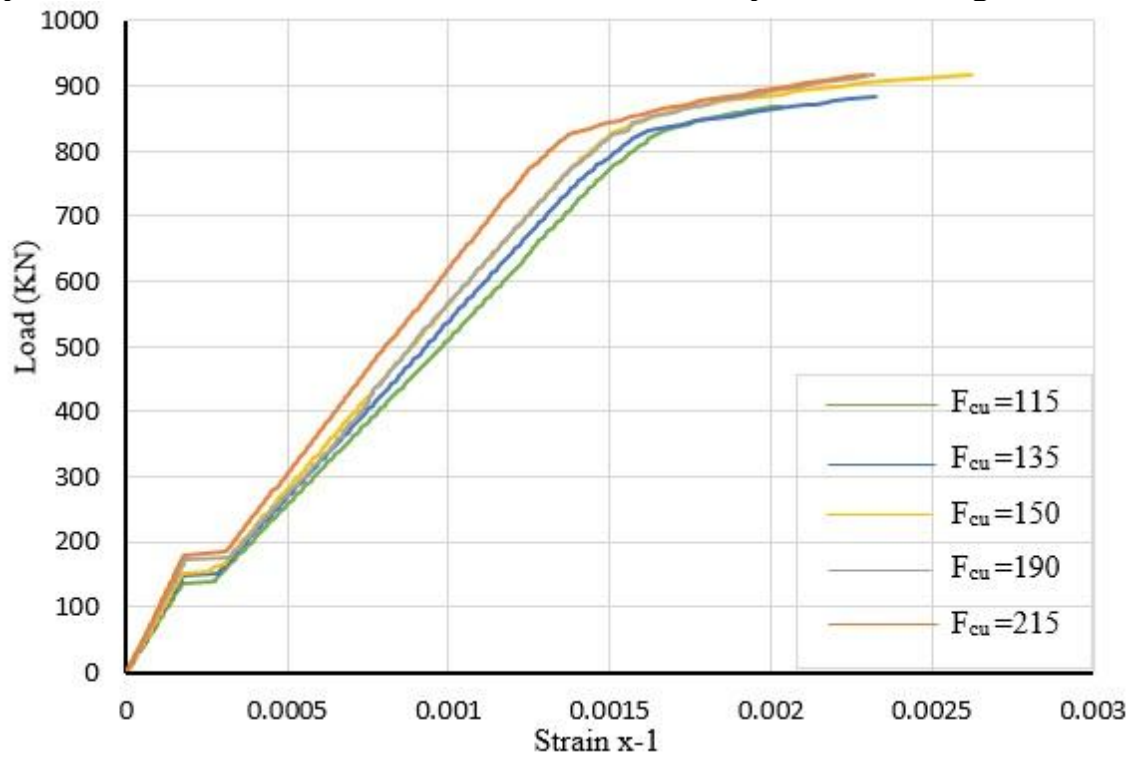

Fig. 13. Load-Midspan Compressive UHPC Strain Curve for $B_{1}, B_{2}, B_{3}, B_{4}$ and $B_{5}$ 


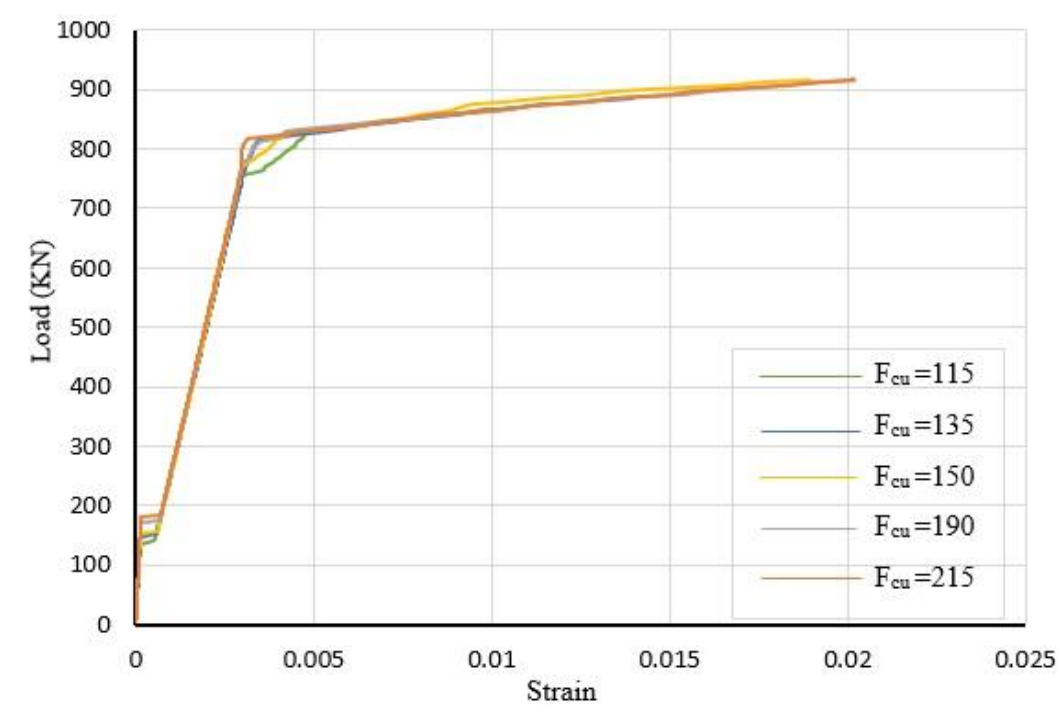

Fig. 14. Load-Midspan Tensile Steel Strain Curve for $B_{1}, B_{2}, B_{3}, B_{4}$ and $B_{5}$

\section{CONCLUSIONS}

This paper presents a numerical study on the uniaxial flexural behavior of ultra high performance concrete beams. The most important conclusions of the conducted parametric study can be summarized as increasing the concrete compressive strength from 115 to $150 \mathrm{MPa}$ led to increase the flexure capacity by $5.4 \%$ and remains constant from 150 to $215 \mathrm{MPa}$. While, the stiffness was decreased by $35 \%$ from 115 to $215 \mathrm{MPa}$. No effect on the crack pattern, the ductility was increased, approximately no effect on the compressive concrete strain and the tensile steel strain at failure was increased by $92 \%$.

\section{REFERENCES}

1. Association Française de Génie Civil (AFGC). (2002). Ultra High Performance FibreReinforced Concretes-Interim Recommendations.

2. Roth, M. J, Boone, N. R, Kinnebrew, P. G, Davis, J. L, Rushing, T. S. (2008). Development of New Protective Solutions to Counter Emerging and Adaptive Threats.

3. [Richard, P, M. Cheyrezy. (1995). Composition of Reactive Powder Concretes. Cement and Concrete Research, 1501-1511.

4. Jungwirth, J, A. Muttoni. (2004). Structural Behavior of Tension Members in UHPC. École Polytechnique Fédérale de Lausanne.

5. Rossi. (2005). Development of New Cement Composite Materials for Construction. Proceedings of the Institution of Mechanical Engineers, Part L: Journal of Materials: Design and Applications, 67-74.

6. In Hwan Yang, Changbin Joh, Byung-Suk Kim. (2010). Structural behavior of ultra high performance concrete beams subjected to bending. Engineering structures, 3478-3487.

7. M.M. Kamal, M.A. Safan, Z.A. Etman, R.A. Salama . (2014). Behavior and strength of beams cast with ultra high strength concrete containing different types of fibers. Housing and Building National Research Center, 55-63.

8. Doo-Yeol Yoo, Young-Soo Yoon . (2015). Structural performance of ultra-highperformance concrete beams with different steel fibers. Engineering Structures, 409-423.

9. M. Singh , A.H. Sheikh, M.S. Mohamed Ali, P. Visintin, M.C. Griffith. (2017). Experimental and numerical study of the flexural behaviour of ultra-high performance fibre reinforced concrete beams. Construction and Building Materials, 12-25. 
10. Venkatesh Kodur, Roya Solhmirzaei, Ankit Agrawal, Esam M Aziz, Parviz Soroushian. (2018). Analysis of flexural and shear resistance of ultra high performance fiber reinforced concrete beams without stirrups. Engineering Structures, 873-884.

11. Doo-Yeol Yoo, Soonho Kim $\square$, Jae-Jin Kim, Booki Chun. (2019). An experimental study on pullout and tensile behavior of ultra-high performance concrete reinforced with various steel fibers. Construction and Building Materials, 46-61.

12. Anis Mohamad Ali, Bj. Farid And A.I.M. Al-Janabi. (1990). Stress-Strain Relationship for Concrete in Compression Madel of Local Materials. JKAU, 2, 183-194.

13. Wasan I. Khalil, Tayfur Y. R. (2013). Flexural Strength of Fibrous Ultra High Performance Reinforced Concrete Beams. ARPN Journal of Engineering and Applied Sciences, 200-214.

14. Sung-woo Shin, Hoon Kang, Jong-mun Ahn, Do-woo Kim . (2010). Flexural capacity of singly reinforced beam with $150 \mathrm{MPa}$ ultra high-strength concrete. Indian Journal of Engineering \& Materials Sciences, 414-426.

15. Ansys mechanical manual version 18. 